\title{
Demethoxycurcumin Promotes Macrophage Cell Population and Phagocytosis in WEHI-3 Cell-generated Leukemia BALB/c Mice In Vivo
}

\author{
YI-JIA LIN ${ }^{1}$, CHIUNG-JU CHEN ${ }^{2,3}$, SHU-CHING HSUEH ${ }^{4}$, MEI-HUI LEE ${ }^{5}$, SHU-FEN PENG ${ }^{6,7}$, \\ HSU-FENG LU ${ }^{8,9}$, KUNG-WEN LU $^{10}$, WEN-WEN HUANG ${ }^{6}$, KUO-CHING LIU ${ }^{11}$, \\ YUNG-LIANG CHEN ${ }^{12}$, YUNG-LUEN SHIH ${ }^{2,13^{*}}$ and JIN-CHERNG LIEN ${ }^{14^{*}}$ \\ ${ }^{1}$ Department of Pathology, Tri-service General Hospital, National Defense Medical Center, Taipei, Taiwan, R.O.C.; \\ ${ }^{2}$ Department of Pathology and Laboratory Medicine, \\ Shin Kong Wu Ho-Su Memorial Hospital, Taipei, Taiwan, R.O.C.; \\ ${ }^{3}$ Jen-Teh Junior College of Medicine, Nursing and Management, Miaoli, Taiwan, R.O.C.; \\ ${ }^{4}$ Division of Hematology and Oncology, Cheng Hsin General Hospital, Taipei, Taiwan, R.O.C.; \\ ${ }^{5}$ Department of Genetic Counseling Center, Changhua Christian Hospital, Changhua, Taiwan, R.O.C.; \\ ${ }^{6}$ Department of Biological Science and Technology, China Medical University, Taichung, Taiwan, R.O.C.; \\ ${ }^{7}$ Department of Medical Research, China Medical University Hospital, Taichung, Taiwan, R.O.C.; \\ ${ }^{8}$ Department of Medical Laboratory Science and Biotechnology, Asia University, Taichung, Taiwan, R.O.C.; \\ ${ }^{9}$ Department of Laboratory Medicine, China Medical University Hospital, Taichung, Taiwan, R.O.C.; \\ ${ }^{10}$ College of Chinese Medicine, School of Post-Baccalaureate Chinese Medicine, \\ China Medical University, Taichung, Taiwan, R.O.C.; \\ ${ }^{11}$ Department of Medical Laboratory Science and Biotechnology, \\ China Medical University, Taichung, Taiwan, R.O.C.; \\ ${ }^{12}$ Department of Medical Laboratory Science and Biotechnology, Yuanpei University, Hsinchu, Taiwan, R.O.C.; \\ ${ }^{13}$ School of Medicine, College of Medicine, Fu-Jen Catholic University, New Taipei, Taiwan, R.O.C.; \\ ${ }^{14}$ School of pharmacy, China Medical University, Taichung, Taiwan, R.O.C.
}

\begin{abstract}
Background/Aim: Demethoxycurcumin (DMC), one of the components of curcuminoids, has antitumor activities in many human cancer cells and is known to induce apoptosis in human leukemia cells. However, there are no reports showing the effects of DMC on the immune response
\end{abstract}

This article is freely accessible online.

\begin{abstract}
*These Authors contributed equally to this study.
Correspondence to: Yung-Luen Shih, Ph.D., Department of Pathology and Laboratory Medicine, Shin Kong Wu Ho-Su Memorial Hospital, No. 95, Wen-Chang Road, Shih-Lin, Taipei city, Taiwan, R.O.C. Tel: +886 228332211 ext. 2128, Fax: +886 228389360, e-mail: t005524@ms.skh.org.tw; Jin-Cherng Lien, Ph.D., School of Pharmacy, China Medical University, No. 91, Hsueh-Shih Road, Taichung, Taiwan, R.O.C. Tel: +886 422053366 ext. 5609, Fax: +886 422053764, e-mail: jclien@mail.cmu.edu.tw
\end{abstract}

Key Words: Demethoxycurcumin (DMC), WEHI-3 cells, macrophages, phagocytosis, leukemia mice. in leukemia mice in vivo. Herein, we evaluated the impact of DMC on immune responses in WEHI-3-generated leukemia mice in vivo. Materials and Methods: Fifty male BALB/c mice were separated randomly into five groups. Group I is normal mice, and groups II-V mice of generated leukemia by WEHI-3 cells. Group II-V mice were intraperitoneally injected with dimethyl sulfoxide (DMSO, as the positive control), 15,30 , and $60 \mathrm{mg} / \mathrm{kg}$ of DMC, respectively, every two days for 14 days. The body weight, blood, peritoneal fluid, liver, and spleen were individually analyzed. Results: DMC did not significantly affect animal appearance and body weight. It decreased liver and spleen weight at a high dose. DMC did not affect the cluster of differentiation 3 (CD3) and CD19 cell populations but induced decrease of CD11b at $30 \mathrm{mg} / \mathrm{kg}$ treatment. However, DMC at low dose significantly increased the cluster of macrophage (Mac-3) cell populations, but at high dose it decreased them. DMC increased macrophage phagocytosis from peripheral blood mononuclear cells at $15 \mathrm{mg} / \mathrm{kg}$ treatment and peritoneal cavity at 15, 30 and $60 \mathrm{mg} / \mathrm{kg}$ of DMC treatments. DMC did not significantly affect the cytotoxic activity of natural killer 
(NK) cells. Furthermore, DMC decreased B and T cell proliferation at high doses. Conclusion: DMC elevated macrophage phagocytosis in leukemia mice in vivo.

Acute myeloid leukemia (AML), an aggressive form of bone marrow cancer, is a hematological malignancy caused by an expansion and accumulation of myeloid blasts within the bone marrow $(1,2)$. AML, the most common leukemia in adults (3), accounts for about $80 \%$ of all adult acute leukemia cases (4) and approximately about three to five cases per 100,000 people (5). In the past years, both chemotherapy and hematopoietic stem cell transplantation were used for treating AML patients. But chemoresistance causes subsequent relapse or progression (6), and the toxicity caused by these treatments leads to a 5-year survival rates below 50\% (7-9). Thus, novel therapeutic strategies for AML patients are urgently needed. The elevated host immune responses against leukemia and the development of new compounds from natural products are required.

Curcuminoids, yellow pigments extracted from turmeric rhizomes, exhibit potent anticancer activities in numerous human cancer cells (10). Curcuminoids consist of at least three major compounds, including curcumin, demethoxycurcumin (DMC), and bisdemethoxycurcumin (BDMC). DMC is one of the main bioactive components of curcuminoids (11), and it is more stable in the blood than other curcuminoids (12). DMC suppressed prostate cancer cell migration and invasion (13) and induced DNA damage and apoptosis in lung cancer cells (14). Recently, we found that DMC significantly reduced tumor weight and volume of HeLa cell-xenograft mice in vivo (15). Moreover, DMC has been shown to decrease the proportion of viable cells in human AML cell lines (HL-60, U937, and MV4-11) (16). However, there are no further reports regarding the effects of DMC on the immune response of leukemia animal models in vivo. The immune response against cancer cells has a well-known humoral component and involves a complex cellular mechanism. Thus, the therapeutic potential of DMC in the adjuvant treatment of AML should be further investigated. The aim of this study was to characterize the immune responses in WEHI-3 cell-generated leukemia $\mathrm{BALB} / \mathrm{c}$ mice after exposure to various doses of DMC.

\section{Materials and Methods}

Materials and reagents. Demethoxycurcumin (DMC) and dimethyl sulfoxide (DMSO) were obtained from Sigma-Aldrich Corp. (St. Louis, MO, USA). Iscove's modified dulbecco's medium (IMDM), Roswell Park Memorial Institute (RPMI)-1640 medium, fetal bovine serum (FBS), L-glutamine, and antibiotics (penicillin-streptomycin) were purchased from Gibco Life Technologies (Carlsbad, CA, USA). Primary antibodies anti-CD3, -CD11b, -CD19, and -Mac-3 were purchased from BD Biosciences Pharmingen Inc. (San Diego, CA, USA). DMC was dissolved in DMSO and stored at $-20^{\circ} \mathrm{C}$ before use.
WEHI-3 cells. The murine acute myelomonocytic WEHI-3 leukemia cell line was purchased from the Food Industry Research and Development Institute (Hsinchu, Taiwan, ROC). Cells were cultured in IMDM medium supplemented with 10\% FBS, 2 mM L-glutamine, and antibiotics (100 units $/ \mathrm{ml}$ penicillin and $100 \mu \mathrm{g} / \mathrm{ml}$ streptomycin) in $75-\mathrm{cm}^{2}$ flasks and placed at $37^{\circ} \mathrm{C}$ in a $5 \% \mathrm{CO}_{2}$ humidified atmosphere. The cultured medium was changed every two days (16).

Male BALB/c mice. Fifty male BALB/c mice (20-23 g at four-weekold) were purchased from the National Laboratory Animal Center (Taipei, Taiwan, ROC). The mice were kept in stainless steel meshbottomed cages with a $12 \mathrm{~h} \mathrm{light/dark} \mathrm{cycle} \mathrm{at} 25 \pm 2^{\circ} \mathrm{C}$ and $50 \pm 10 \%$ humidity, were fed with standard food and water in the animal center of China Medical University (Taichung, Taiwan, ROC). We followed the institutional guidelines for animal welfare, and this study was approved by the Institutional Animal Care and Use Committee (IACUC) of China Medical University (Taichung, Taiwan, ROC) (approval ID: CMUIACUC-2019-019) (17).

Treatment of animals with DMC. Fifty BALB/c mice were randomized and divided into five groups $(\mathrm{N}=10)$. Group I: normal animals treated with normal diet (control group); Groups II-V: animals were intraperitoneally injected with $8 \times 10^{4}$ WEHI-3 leukemia cells to generate leukemia groups. Group II mice, as the positive control (WEHI-3 control group), were intraperitoneally injected with DMSO; Group III-V mice were treated with 15, 30, and $60 \mathrm{mg} / \mathrm{kg}$ of DMC in DMSO, respectively. DMSO and DMC were individually administered every two days for 14 days (a total of seven times). During the treatment, each animal was individually weighed and sacrificed at the end of experimental periods as described previously (17).

Measurements of cell populations. At the end of the experimental treatments, mice from each group were individually weighed, and blood, livers, and spleens were collected. The red blood cells were treated with $1 \times$ Pharm Lyse $^{\mathrm{TM}}$ lysing buffer (BD Biosciences Pharmingen Inc., San Diego, CA, USA) to lyse the red blood cells ( $1 \mathrm{ml} /$ mouse). Leukocytes from each mouse were individually stained with phycoerythrin (PE)-labeled anti-mouse CD3 or CD19, or fluorescein isothiocyanate (FITC)-labeled anti-mouse CD11b or Mac-3 antibodies (BD Biosciences Pharmingen Inc.) for $30 \mathrm{~min}$. After samples were washed with phosphate-buffered saline (PBS), their cell population (markers) were analyzed by flow cytometry, as previously described $(17,18)$.

Measurements of macrophage phagocytosis. Macrophages were individually isolated from peripheral blood mononuclear cells (PBMCs) and peritoneum cavity as previously described (17-19). Isolated macrophages from PBMCs or peritoneum cavity of individual mice were separately added to the plates containing 50 $\mu \mathrm{l}$ of target FITC-conjugated Escherichia coli and then were performed phagocytosis assay by using flow cytometer according to the PHAGOTEST ${ }^{\circledR}$ kit manufacturer's instructions (ORPEGEN Pharma Gesellschaft für biotechnologische, Heidelberg, Germany). CellQuest software (Becton Dickinson) was used to quantify each phagocytosis as described previously (18).

Measurements of natural killer (NK) cell cytotoxic activity. Isolated splenocytes $\left(2.5-5 \times 10^{5}\right.$ cells/well $)$ from each group were placed in 12 -well plates containing $1 \mathrm{ml}$ of RPMI-1640 medium. YAC-1 cells 

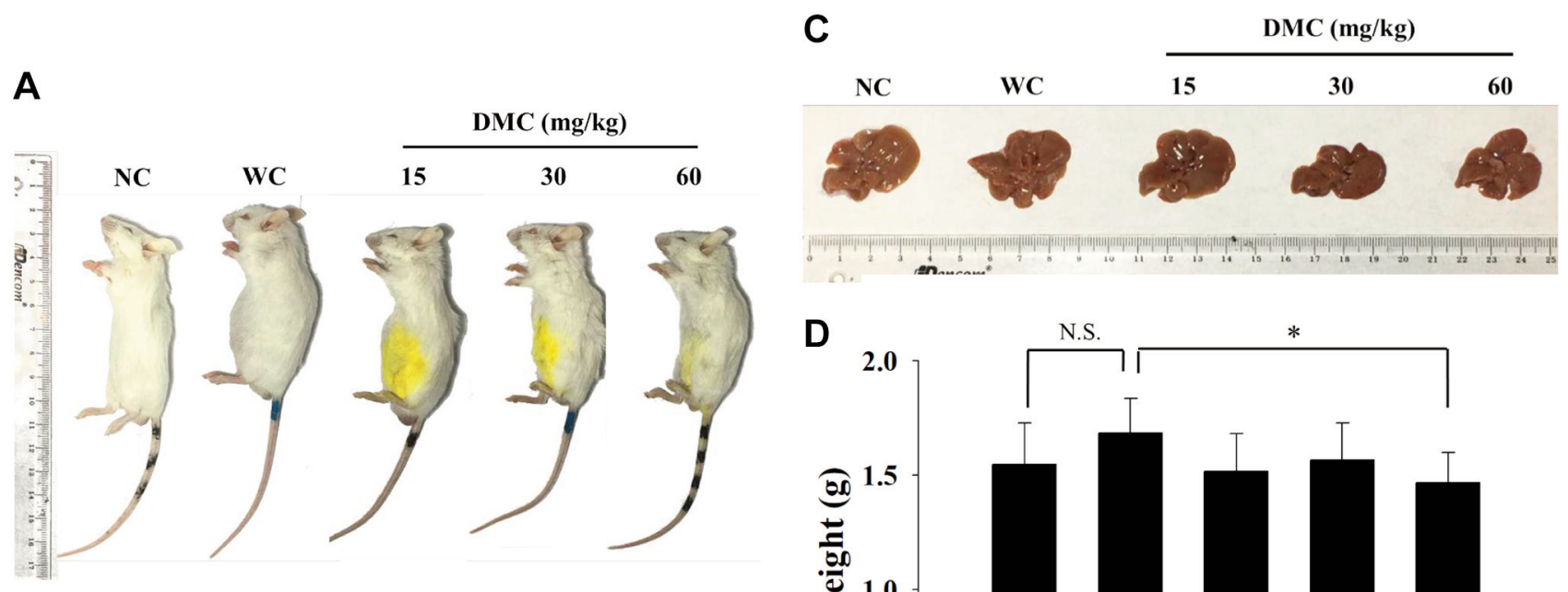

B
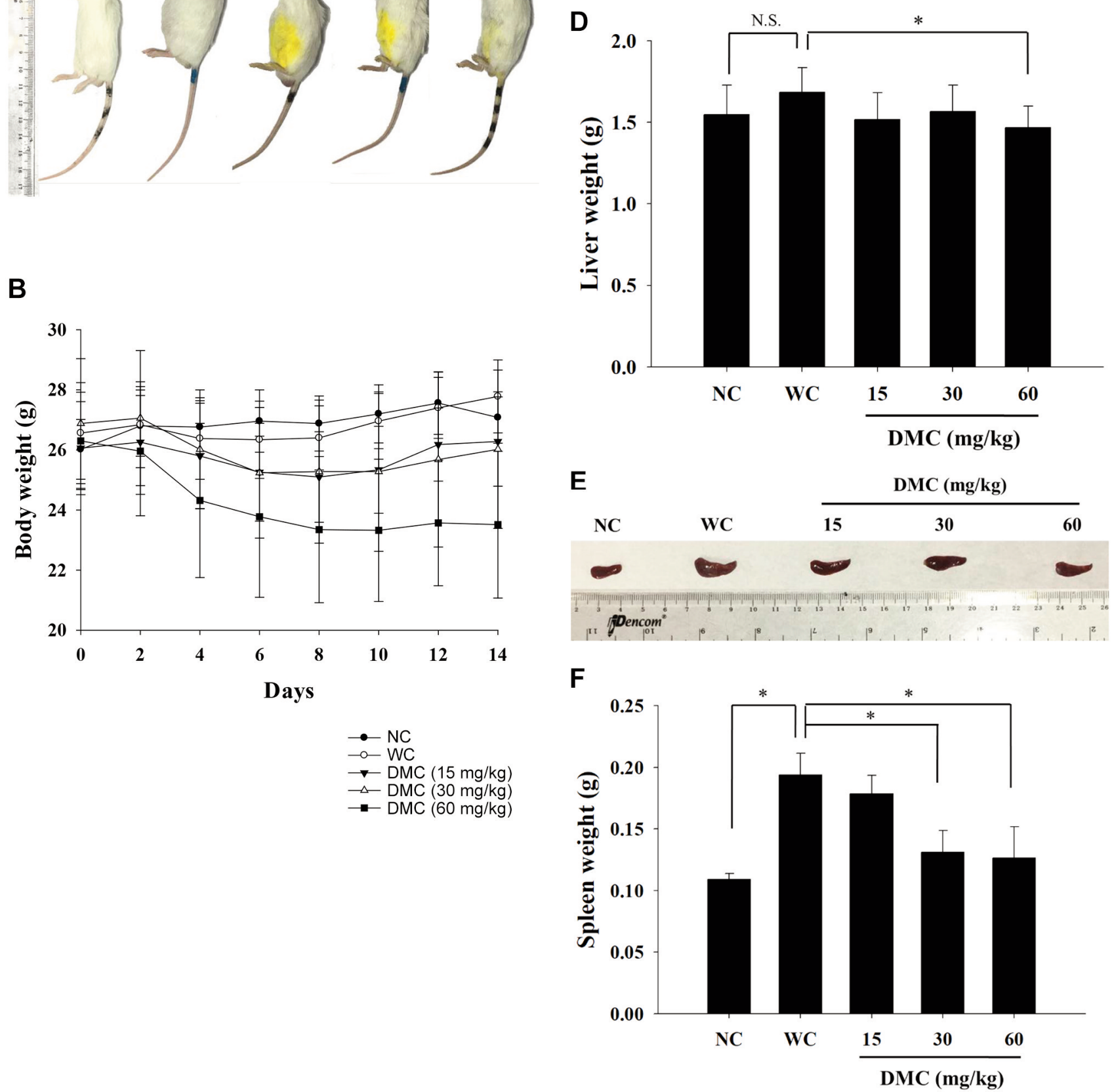

Figure 1. DMC affected the body, liver, and spleen weight of WEHI-3 cell-generated leukemia BALB/c mice. Group I mice (normal mice; N=10) were normal control. Groups II-V mice were injected with WEHI-3 cells to generate leukemia. Group II mice were intraperitoneally injected with DMSO as a positive control; Group III-V mice with 15, 30, and $60 \mathrm{mg} / \mathrm{kg}$ of DMC, respectively. (A) Representative animal appearance; (B) body weight change for 14 days; $(C)$ representative liver; $(D)$ liver weight; $(E)$ representative spleen; $(F)$ spleen weight. ${ }^{*} p<0.05$, was considered to indicate a statistically significant difference. 
A

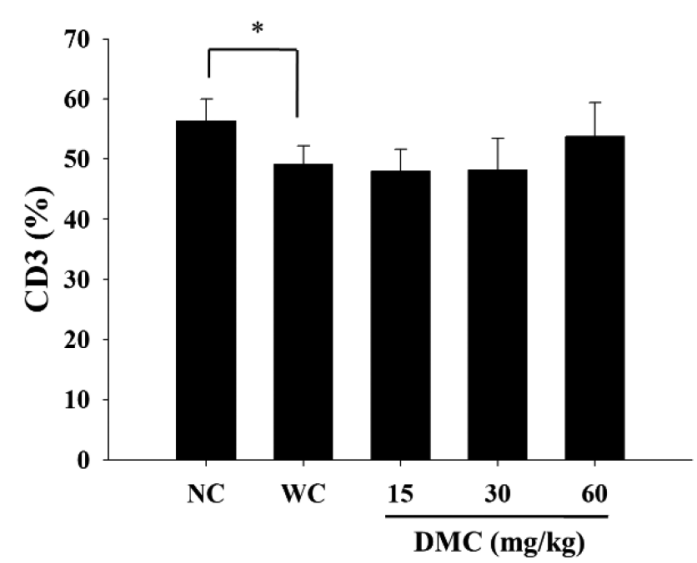

C

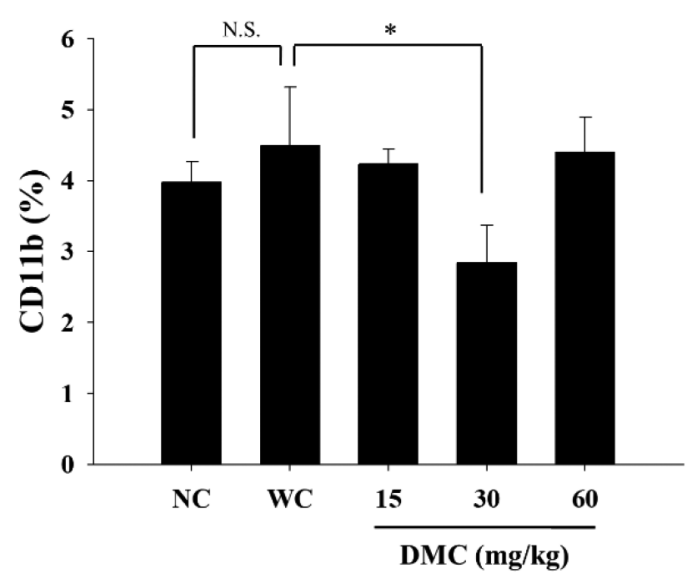

B
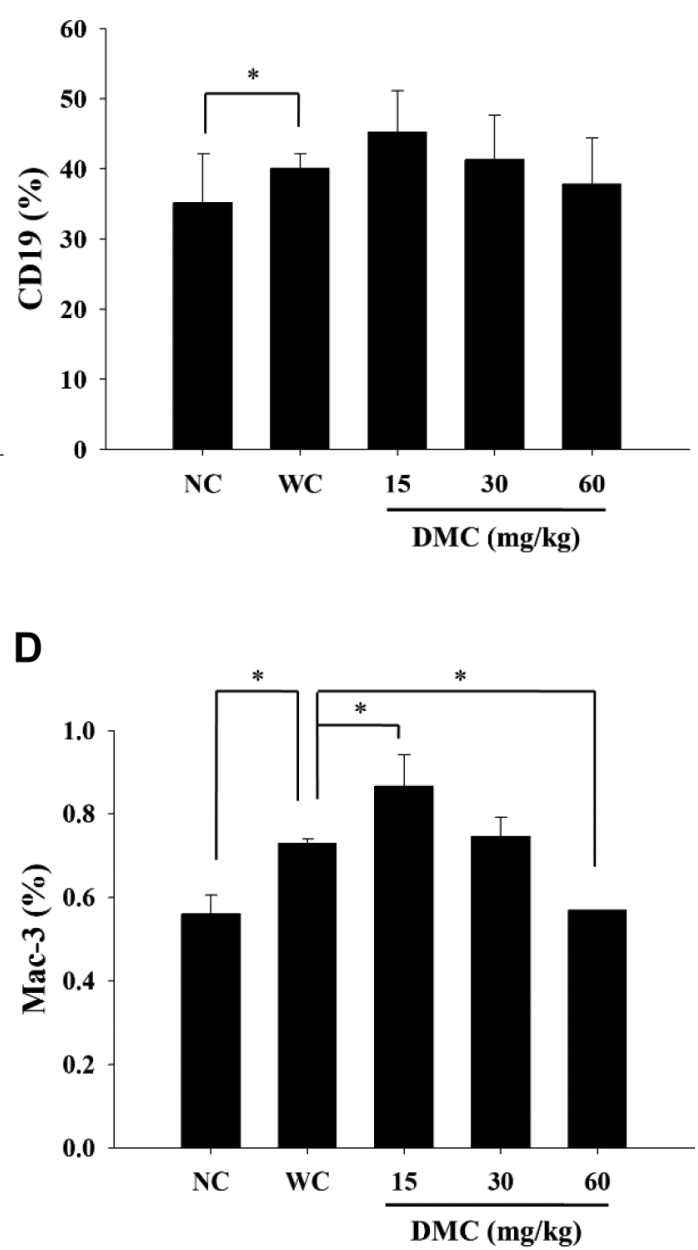

Figure 2. DMC affected the levels of cell markers in white blood cells from leukemia BALB/c mice. Blood samples were collected from each mouse and were further analyzed for cell markers by flow cytometry, as described in the Materials and Methods section. A: CD3; B: CD19; C: CD11b; and D: Mac-3. ${ }^{*} p<0.05$, was considered to indicate a statistically significant difference.

$\left(1 \times 10^{4}\right.$ cells $)$, as the target of splenocytes, were added to cells with PKH-67/Dil.C buffer (Sigma-Aldrich) for $2 \mathrm{~min}$ at $25^{\circ} \mathrm{C}$. Followed $2 \mathrm{ml}$ of PBS was added to the well for $1 \mathrm{~min}$, and $4 \mathrm{ml}$ of medium was added and incubated for $10 \mathrm{~min}$. All samples were centrifuged at $290 \times g$ for $2 \mathrm{~min}$. NK cell cytotoxic activity was measured by flow cytometry as described previously (18).

Measurements of $T$ and $B$ cell proliferation. Splenocytes $\left(1 \times 10^{5}\right.$ cells/well) in $100 \mu \mathrm{l}$ were added to 12 -well plates containing $100 \mu \mathrm{l}$ of RPMI-1640 medium. Splenocytes were stimulated with concanavalin A (Con A, $1 \mu \mathrm{g} / \mathrm{ml}$ ) for five days and with lipopolysaccharide (LPS, $1 \mu \mathrm{g} / \mathrm{ml}$ ) for three days for measuring the $\mathrm{T}$ and $\mathrm{B}$ cell proliferation, respectively. All samples were analyzed for $\mathrm{T}$ and $\mathrm{B}$ cell proliferation by using CellTiter 96 Aqueous One Solution Cell Proliferation Assay kit (Promega, Madison, WI, USA) as previously described (18).

Statistical analysis. All results were expressed as mean \pm standard deviation (SD). One-way ANOVA was used to analyze the statistical significance among the two groups. ${ }^{*} p<0.05$ was considered to indicate a statistically significant difference.

\section{Results}

DMC affected the weight of the body, liver, and spleen of leukemia $B A L B / c$ mice. Animals were separated into normal mice $(\mathrm{N}=10 ; \mathrm{NC})$ and leukemia mice $(\mathrm{N}=40)$. The leukemia mice were randomly divided into four groups: one group was the positive control (WC), and the other three were treated with 15,30 , and $60 \mathrm{mg} / \mathrm{kg}$ of DMC every two days for 14 days. At the end of the experimental periods, representative animal body pictures are presented in Figure 1A, indicating that DMC did not significantly affect animal appearance. DMC also did not change animal's body weight compared to positive control groups (Figure 1B). At the end of treatment, mice were sacrificed, and the individual livers and spleens 
A

PBMC

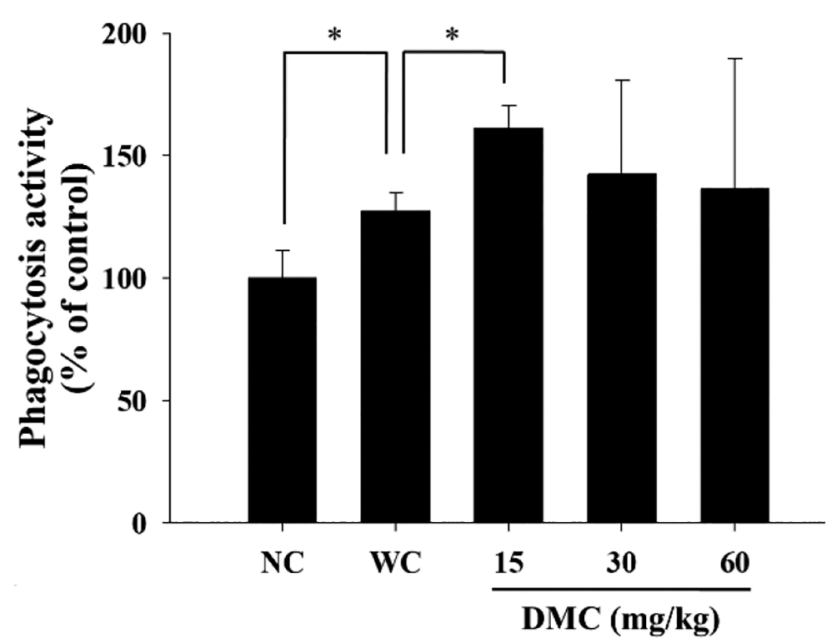

B

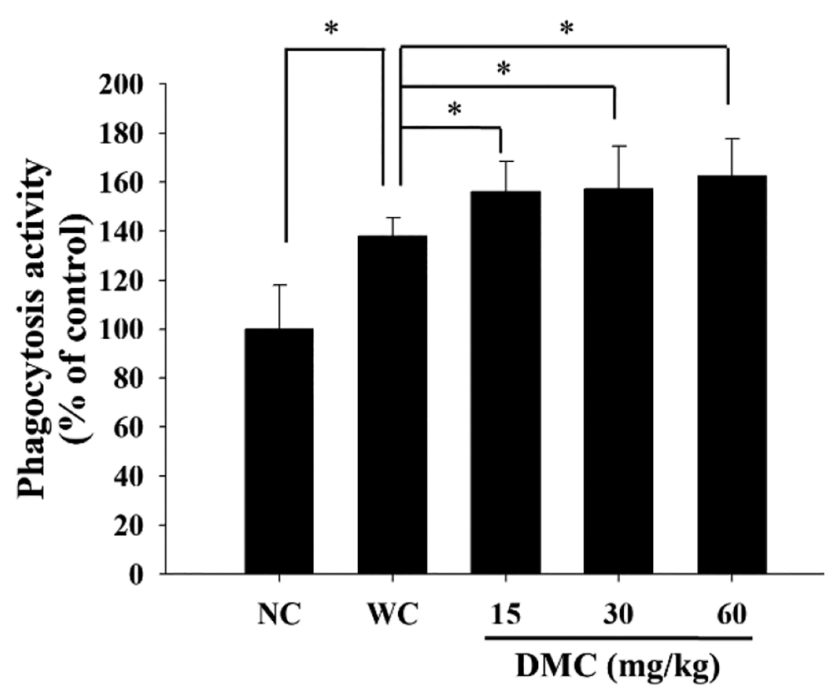

Figure 3. DMC affected macrophage phagocytosis from peripheral blood mononuclear cells (PBMCs) and peritoneal cavity of leukemia BALB/C mice. Blood and peritoneal fluid samples were collected from individual mice. Phagocytosis of macrophages from PBMCs (A) and peritoneum (B) were measured by flow cytometry and quantified as described in the Materials and Methods section. *p $<0.05$, was considered to indicate a statistically significant difference.

were isolated. Representative liver pictures are presented in Figure 1C. DMC significantly decreased liver weight only at $60 \mathrm{mg} / \mathrm{kg}$ treatment (Figure 1D). Representative spleen pictures are presented in Figure 1E. DMC significantly decreased spleen weight at 30 and $60 \mathrm{mg} / \mathrm{kg}$ treatment but did not affect at $15 \mathrm{mg} / \mathrm{kg}$ treatment (Figure $1 \mathrm{~F}$ ).

DMC affected cell markers of white blood cells from leukemia BALB/c mice. The CD3, CD19, CD11b, and Mac3 markers were measured in blood samples from each group by flow cytometry, and results are shown in Figure 2A, B, C and D. Results indicated that DMC did not significantly promote CD3 (Figure 2A) nor CD19 (Figure 2B) at the three doses of DMC treatment when compared to positive controls. DMC at $30 \mathrm{mg} / \mathrm{kg}$ significantly reduced the cell population with CD11b marker (Figure 2C). But DMC at a low dose $(15 \mathrm{mg} / \mathrm{kg})$ significantly increased cells with the Mac-3 marker; however, DMC at $60 \mathrm{mg} / \mathrm{kg}$ led to decreased Mac-3 marker compared to the positive control (Figure 2D).

DMC affected macrophage phagocytosis from PBMC and peritoneal cavity of leukemia $B A L B / c$ mice. The phagocytosis activity of macrophages isolated from PBMC and peritoneum cavity was measured by a flow cytometer. As shown in Figure $3 \mathrm{~A}$ and B, DMC treatment at $15 \mathrm{mg} / \mathrm{kg}$ significantly increased macrophage phagocytosis of PBMC (Figure 3A). However, three doses (15, 30, and $60 \mathrm{mg} / \mathrm{kg}$ ) of DMC significantly increased macrophage phagocytosis from the peritoneum cavity compared to positive control groups (Figure 3B).

DMC affected the cytotoxic activity of natural killer cells from leukemia BALB/c mice. YAC-1 cells were used as targets for measuring NK cell cytotoxic activity that were assayed by a flow cytometer, and results are shown in Figure 4. Results indicated that DMC did not significantly increase NK cells' cytotoxic activity at 15,30 , and $60 \mathrm{mg} / \mathrm{kg}$ treatment at targets ratio at 25:1 and 50:1 when compared to positive control groups.

$D M C$ affected $B$ and $T$ cell proliferation from leukemia $B A L B / c$ mice. Splenocytes from individual mice were assayed for $\mathrm{B}$ and $\mathrm{T}$ cell proliferation, and results are presented in Figure $5 \mathrm{~A}$ and $\mathrm{B}$. The results indicated that both doses of DMC treatment (30 and $60 \mathrm{mg} / \mathrm{kg}$ ) significantly decreased B (Figure 5A) and T (Figure 5B) cell proliferation when compared to positive control groups.

\section{Discussion}

Numerous studies have demonstrated that curcumin and its analogs, such as DMC and BDMC, possess pharmacological activities, including antioxidant, anti-inflammatory, and antiproliferative activities $(19,20)$. Moreover, DMC has better anti-inflammatory and anticancer activity compared to curcumin $(21,22)$. DMC reduced the viable cell number of human leukemia cells (16). Recently, we found that DMC 


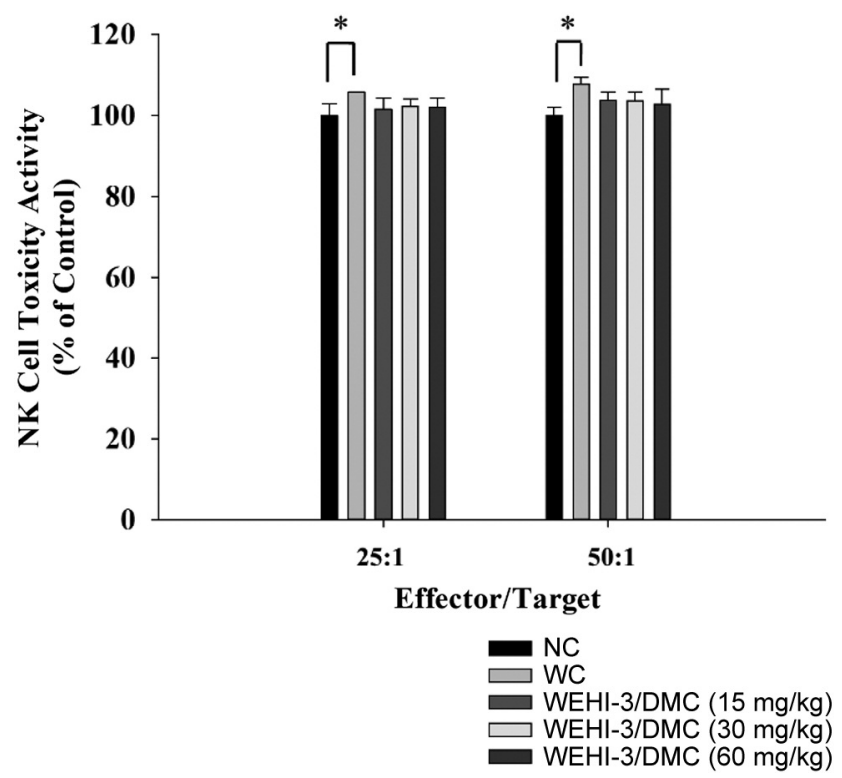

Figure 4. DMC affected the cytotoxic activity of natural killer cells in leukemia BALB/c mice. Isolated splenocytes were placed in $1 \mathrm{ml}$ of RPMI 1640 medium in 12-well plates. Target YAC-1 cells in serum-free RPMI 1640 medium and the PKH-67/Dil.C buffer were added to the cells, and NK cell cytotoxic activity was measured by flow cytometry as described in Materials and Methods. ${ }^{*} p<0.05$, was considered to indicate a statistically significant difference.

reduced tumor weight and volume of HeLa cell xenograft mice in vivo (15). However, there is no available information showing that DMC can stimulate immune responses in a leukemia animal model. Thus, we investigated the effects of DMC on WEHI-3 cell-generated leukemia mice in vivo and results showed that DMC treatment led to increasing macrophage phagocytosis in vivo.

At first, we used mouse leukemia cells (WEHI-3) to generate acute leukemia mice, and this mouse model has been well documented for examining affected immune responses in vivo. Thus, based on the reliability and internal validity of mice in vivo we could mimick human acute leukemia for further immune response studies which elicited in BALB/c strain mice model.

In the present study, a total of fifty mice were used and ten normal mice were considered as control group; while forty mice were the "generated acute leukemia mice" by intraperitoneally injecting WEHI-3 cells as described previously (17). Generated leukemia mice were randomly divided into four groups: one for normal diet as the positive control group, and three groups were intraperitoneally injected with DMC $(15,30$, and $60 \mathrm{mg} / \mathrm{kg})$ per two days. During treatment, animal behavior and body weight were recorded. At the end of treatment, blood samples were collected for measuring cell markers and phagocytosis. Liver
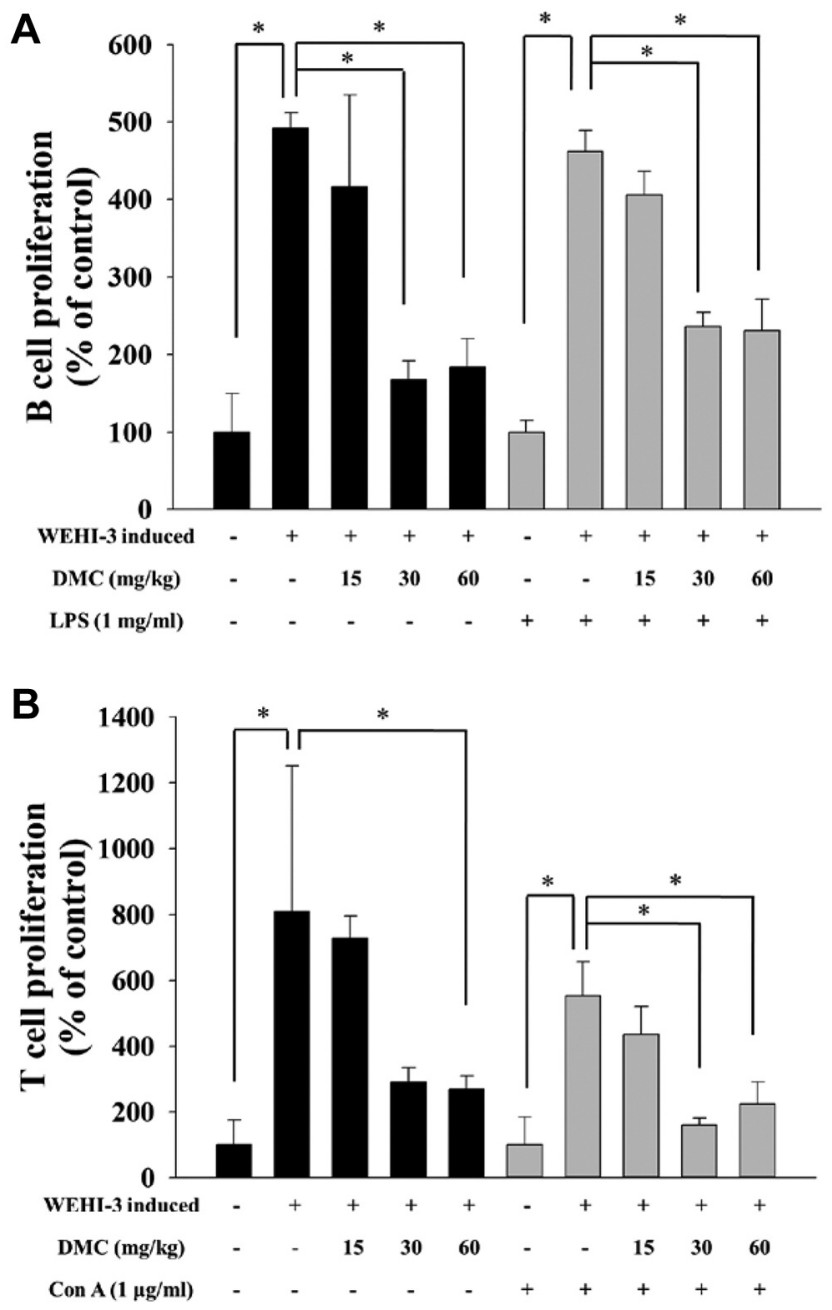

Figure 5. DMC affected B and T cell proliferation in leukemia BALB/c mice. Isolated splenocytes were pretreated with lipopolysaccharides $(L P S)$ and concanavalin $A(C o n A)$ for $B(A)$ and $T(B)$ cell proliferation and were analyzed by flow cytometry as described in the Materials and Methods section. ${ }^{*} p<0.05$, was considered to indicate a statistically significant difference.

and spleen samples were collected, and splenocytes were also isolated for measuring the NK cell activities and B and $\mathrm{T}$ cell proliferation. This is the first report evaluating how DMC affects immune responses in leukemia mice in vivo.

Based on Figure 1A and B, DMC did not significantly affect the appearance and body weight of leukemia mice compared to the control group during treatment. This agrees with other reports, showing that curcumin and its analogs are safe and no-toxic drugs (23). Therefore, DMC offers the properties of high anticancer activity, low toxicity, and relative safety. Liver samples from each group also did not show any significant difference between DMC-treated and positive controls (Figure 1C); however, DMC significantly 
decreased liver weight only at $60 \mathrm{mg} / \mathrm{kg}$ treatment (Figure 1D). DMC significantly decreased spleen weight at 30 and 60 $\mathrm{mg} / \mathrm{kg}$ treatment but had no affect at $15 \mathrm{mg} / \mathrm{kg}$ (Figure $1 \mathrm{~F}$ ). Increased spleen weight is recognized to be a marker for WEHI-3 cell-generated leukemia mouse. However, due to the poor water solubility in the present studies, we used DMSO to dissolve DMC for intraperitoneal treatment in leukemia mice. Other reports also show that the low bioavailability and rapid metabolism of DMC limit its clinical application (24).

Results from cell marker (cell population) assay in blood samples showed that DMC treatment did not significantly elevate CD3 (Figure 2A) and CD19 (Figure 2B) markers but decreased CD11b (Figure 2C) markers at DMC $30 \mathrm{mg} / \mathrm{kg}$ treatment. Other studies demonstrated that $\mathrm{T}$ cells (CD3), B cells (CD19), and monocytes (CD11b) play critical roles in immune responses (25). Therefore, in the present study, we found that DMC did not promote T cells, B cells, and monocyte populations. However, DMC at $15 \mathrm{mg} / \mathrm{kg}$ treatment significantly increased the cell population of Mac3 (Figure 2D). The T-cell-dependent antibody response, one of the most sensitive indicators of immune integrity, is involved the cooperation of numerous cell types, including B cells, T cells, and macrophages (26). It is well known that macrophages belong to innate immune cells, and it is one of the antigen-presenting cells to survey the body for pathogens and damaged tissues. Thus, we further investigated whether or not DMC treatment affects macrophage phagocytosis.

It is well known that diet has a significant effect on the immune of normal and diseased mice; therefore, appropriate animal models help examine chemical-affected immune responses in vivo. For measuring macrophage phagocytosis, macrophages were isolated from the blood and peritoneum of mice after exposure to DMC. Cells (macrophages) were incubated with the target Escherichia coli conjugated with fluorescence and then assay by flow cytometer. Results indicated that DMC at $15 \mathrm{mg} / \mathrm{kg}$ treatment significantly increased macrophage phagocytosis from PBMC (Figure $3 \mathrm{~A}$ ); however, DMC at 15,30 , and $60 \mathrm{mg} / \mathrm{kg}$ treatment increased macrophage phagocytosis from peritoneum (Figure $3 \mathrm{~B})$. We recently demonstrated that $\mathrm{DMC}$ could decrease the tumor size of cervical cancer cells in xenograft mice; however, the mononuclear phagocyte activities in leukemia mice are not available. Thus, herein, our findings showed that DMC can increase the phagocytic activity of macrophages in leukemia mice. The reason for examining macrophage phagocytes from blood and peritoneum is that various tissue macrophages and their precursors are presented in the mononuclear phagocyte system (27). The precursor cells are presented in the bone marrow and other hemopoietic organs transported by the bloodstream are named monocytes and moved to tissues called tissue macrophages (28). Results from Figure 4 showed that DMC did not affect the cytotoxic effects of NK cells in leukemia mice. However, at 30 and $60 \mathrm{mg} / \mathrm{kg}$ treatment, DMC significantly decreased B (Figure 5A) and T cell (Figure 5B) proliferation after LPS and Con A stimulation, respectively. These results are similar as those shown in Figure 2A and B indicating that DMC did not affect the cluster differentiation of CD19 (B cells) and CD3 (T cells) in the blood samples. Therefore, the factors involved in these results that need further investigations the future.

In conclusion, DMC at $60 \mathrm{mg} / \mathrm{kg}$ treatment reduced liver and spleen weight, decreased $\mathrm{B}$ and $\mathrm{T}$ cell proliferation, however, decreased CD11b cell population at $30 \mathrm{mg} / \mathrm{kg}$ treatment. DMC at $15 \mathrm{mg} / \mathrm{kg}$ treatment increased macrophage's phagocytosis from PBMC, however, DMC at $15-60 \mathrm{mg} / \mathrm{kg}$ treatment increased macrophage's phagocytosis from peritoneal cavity of leukemia BALB/c mice. Thus, we suggest that DMC modified immune responses via promoting macrophage cell population and macrophage phagocytosis in WEHI-3 cell generated leukemia BALB/c mice in vivo.

\section{Conflicts of Interest}

The Authors confirm that there are no conflicts of interest.

\section{Authors' Contributions}

Study conception and design: YJL, YLS, and JCL; Acquisition of data: YJL, CJC, SCH, MHL, and HFL; Analysis and interpretation of data: YJL, SFP, KWL, WWH, KCL, and YLC; Drafting of manuscript: YJL, YLS, and JCL; Critical revision: YLS, and JCL. All Authors discussed the results and commented on the article.

\section{Acknowledgements}

This study was supported by the Grant 108-10 from Cheng Hsin General Hospital and 2021SKHAND006 from Shin Kong Wu HoSu Memorial Hospital, Taipei, Taiwan. This study was also supported by the Grant CMU109-S-52 from China Medical University, Taichung, Taiwan.

\section{References}

1 Döhner H, Estey E, Grimwade D, Amadori S, Appelbaum FR, Büchner T, Dombret H, Ebert BL, Fenaux P, Larson RA, Levine RL, Lo-Coco F, Naoe T, Niederwieser D, Ossenkoppele GJ, Sanz M, Sierra J, Tallman MS, Tien HF, Wei AH, Löwenberg B and Bloomfield CD: Diagnosis and management of AML in adults: 2017 ELN recommendations from an international expert panel. Blood 129(4): 424-447, 2017. PMID: 27895058. DOI: 10.1182/blood-2016-08-733196

2 O'Donnell MR, Tallman MS, Abboud CN, Altman JK, Appelbaum FR, Arber DA, Bhatt V, Bixby D, Blum W, Coutre SE, De Lima M, Fathi AT, Fiorella M, Foran JM, Gore SD, Hall AC, Kropf P, Lancet J, Maness LJ, Marcucci G, Martin MG, Moore JO, Olin R, Peker D, Pollyea DA, Pratz K, Ravandi F, Shami PJ, Stone RM, Strickland SA, Wang ES, Wieduwilt M, Gregory $\mathrm{K}$ and Ogba N: Acute myeloid leukemia, Version 
3.2017, NCCN clinical practice guidelines in oncology. J Natl Compr Canc Netw 15(7): 926-957, 2017. PMID: 28687581. DOI: $10.6004 /$ jncen.2017.0116

3 Eaves CJ and Humphries RK: Acute myeloid leukemia and the Wnt pathway. N Engl J Med 362(24): 2326-2327, 2010. PMID: 20554989. DOI: 10.1056/NEJMcibr1003522

4 Siegel RL, Miller KD and Jemal A: Cancer statistics, 2017. CA Cancer J Clin 67(1): 7-30, 2017. PMID: 28055103. DOI: $10.3322 /$ caac. 21387

5 Dores GM, Devesa SS, Curtis RE, Linet MS and Morton LM: Acute leukemia incidence and patient survival among children and adults in the United States, 2001-2007. Blood 119(1): 34-43, 2012. PMID: 22086414. DOI: 10.1182/blood-2011-04-347872

6 Lokody I: Drug resistance: Overcoming resistance in acute myeloid leukaemia treatment. Nat Rev Cancer 14(7): 452-453, 2014. PMID: 24957938. DOI: $10.1038 / \mathrm{nrc} 3776$

7 Lichtenegger FS, Krupka C, Haubner S, Köhnke T and Subklewe M: Recent developments in immunotherapy of acute myeloid leukemia. J Hematol Oncol 10(1): 142, 2017. PMID: 28743264. DOI: 10.1186/s13045-017-0505-0

8 Padma VV: An overview of targeted cancer therapy. Biomedicine (Taipei) 5(4): 19, 2015. PMID: 26613930. DOI: 10.7603/s40681-015-0019-4

9 Roboz GJ: Current treatment of acute myeloid leukemia. Curr Opin Oncol 24(6): 711-719, 2012. PMID: 23014187. DOI: $10.1097 / \mathrm{CCO} .0 \mathrm{~b} 013 \mathrm{e} 328358 \mathrm{f} 62 \mathrm{~d}$

10 Imran M, Ullah A, Saeed F, Nadeem M, Arshad MU and Suleria HAR: Cucurmin, anticancer, \& antitumor perspectives: A comprehensive review. Crit Rev Food Sci Nutr 58(8): 1271-1293, 2018. PMID: 27874279. DOI: 10.1080/10408398.2016.1252711

11 Al Ayoub Y, Gopalan RC, Najafzadeh M, Mohammad MA, Anderson D, Paradkar A and Assi KH: Development and evaluation of nanoemulsion and microsuspension formulations of curcuminoids for lung delivery with a novel approach to understanding the aerosol performance of nanoparticles. Int J Pharm 557: 254-263, 2019 PMID: 30597263. DOI: 10.1016/j.ijpharm.2018.12.042

12 Quitschke WW: Differential solubility of curcuminoids in serum and albumin solutions: implications for analytical and therapeutic applications. BMC Biotechnol 8: 84, 2008. PMID: 18990234. DOI: 10.1186/1472-6750-8-84

13 Ni X, Zhang A, Zhao Z, Shen Y and Wang S: Demethoxycurcumin inhibits cell proliferation, migration and invasion in prostate cancer cells. Oncol Rep 28(1): 85-90, 2012. PMID: 22552297. DOI: 10.3892/or.2012.1783

14 Ko YC, Lien JC, Liu HC, Hsu SC, Lin HY, Chueh FS, Ji BC, Yang MD, Hsu WH and Chung JG: Demethoxycurcumininduced DNA damage decreases DNA repair-associated protein expression levels in NCI-H460 human lung cancer cells. Anticancer Res 35(5): 2691-2698, 2015. PMID: 25964547.

15 Chueh FS, Lien JC, Chou YC, Huang WW, Huang YP, Huang JY, Kuo JY, Huang WN, Sheng SY, Tung HY, Chen HY and Peng SF: Demethoxycurcumin inhibits in vivo growth of xenograft tumors of human cervical cancer cells. In Vivo 34(5): 2469-2474, 2020. PMID: 32871774. DOI: 10.21873/invivo.12062

16 Hsiao PC, Chang JH, Lee WJ, Ku CC, Tsai MY, Yang SF and Chien MH: The curcumin analogue, EF-24, triggers p38 MAPKmediated apoptotic cell death via inducing PP2A-modulated ERK deactivation in human acute myeloid leukemia cells. Cancers (Basel) 12(8): 2163, 2020. PMID: 32759757. DOI: $10.3390 /$ cancers 12082163
17 Fan MJ, Yeh PH, Lin JP, Huang AC, Lien JC, Lin HY and Chung JG: Anthocyanins from black rice (Oryza sativa) promote immune responses in leukemia through enhancing phagocytosis of macrophages in vivo. Exp Ther Med 14(1): 59-64, 2017. PMID: 28672893. DOI: 10.3892/etm.2017.4467

18 Lu HF, Tung WL, Yang JS, Huang FM, Lee CS, Huang YP, Liao WY, Chen YL and Chung JG: In vitro suppression of growth of murine WEHI-3 leukemia cells and in vivo promotion of phagocytosis in a leukemia mice model by indole-3-carbinol. J Agric Food Chem 60(31): 7634-7643, 2012. PMID: 22775144. DOI: $10.1021 /$ jf300963t

19 Sandur SK, Pandey MK, Sung B, Ahn KS, Murakami A, Sethi G, Limtrakul P, Badmaev V and Aggarwal BB: Curcumin, demethoxycurcumin, bisdemethoxycurcumin, tetrahydrocurcumin and turmerones differentially regulate anti-inflammatory and antiproliferative responses through a ROS-independent mechanism. Carcinogenesis 28(8): 1765-1773, 2007. PMID: 17522064. DOI: $10.1093 / \mathrm{carcin} / \mathrm{bgm} 123$

20 Simon A, Allais DP, Duroux JL, Basly JP, Durand-Fontanier S and Delage $\mathrm{C}$ : Inhibitory effect of curcuminoids on MCF-7 cell proliferation and structure-activity relationships. Cancer Lett 129(1): 111-116, 1998. PMID: 9714342. DOI: 10.1016/s03043835(98)00092-5

21 Lee JW, Hong HM, Kwon DD, Pae HO and Jeong HJ: Dimethoxycurcumin, a structural analogue of curcumin, induces apoptosis in human renal carcinoma caki cells through the production of reactive oxygen species, the release of cytochrome $\mathrm{C}$, and the activation of caspase-3. Korean J Urol 51(12): 870878, 2010. PMID: 21221209. DOI: 10.4111/kju.2010.51.12.870

22 Zhang LJ, Wu CF, Meng XL, Yuan D, Cai XD, Wang QL and Yang JY: Comparison of inhibitory potency of three different curcuminoid pigments on nitric oxide and tumor necrosis factor production of rat primary microglia induced by lipopolysaccharide. Neurosci Lett 447(1): 48-53, 2008. PMID: 18838107. DOI: 10.1016/j.neulet.2008.09.067

23 Teng YN, Hsieh YW, Hung CC and Lin HY: Demethoxycurcumin modulates human P-glycoprotein function via uncompetitive inhibition of ATPase hydrolysis activity. J Agric Food Chem 63(3): 847-855, 2015. PMID: 25594233. DOI: 10.1021/jf5042307

24 Datta S, Misra SK, Saha ML, Lahiri N, Louie J, Pan D and Stang PJ: Orthogonal self-assembly of an organoplatinum(II) metallacycle and cucurbit[8]uril that delivers curcumin to cancer cells. Proc Natl Acad Sci U.S.A. 115(32): 8087-8092, 2018. PMID: 30038010. DOI: 10.1073/pnas.1803800115

25 Arpinati $M$ and Curti A: Immunotherapy in acute myeloid leukemia. Immunotherapy 6(1): 95-106, 2014. PMID: 24341888. DOI: $10.2217 /$ imt.13.152

26 Anderson SE, Munson AE and Meade BJ: Analysis of immunotoxicity by enumeration of antibody-producing B cells. Curr Protoc Toxicol Chapter 18: Unit18.11, 2006. PMID: 23045130. DOI: 10.1002/0471140856.tx1811s29

27 Haniffa M, Bigley V and Collin M: Human mononuclear phagocyte system reunited. Semin Cell Dev Biol 41: 59-69, 2015. PMID: 25986054. DOI: 10.1016/j.semcdb.2015.05.004

28 Gordon S and Cohn ZA: The macrophage. Int Rev Cytol 36: 171214, 1973. PMID: 4271722. DOI: 10.1016/s0074-7696(08)60218-1

Received May 31, 2021

Revised June 29, 2021

Accepted July 16, 2021 